\title{
POR UNA HISTORIA DE LA SOCIABILIDAD FEMENINA: ALGUNAS REFLEXIONES
}

\author{
por \\ DANIÈLE BUSSY GENEVOIS \\ E.R.E.S.C.E.C., Université de Paris VIII
}

RESUMEN: Aplicar los instrumentos de análisis de la sociabilidad a las mujeres españolas no significa contentarse con la aplicación de una categoría cómoda a un objeto de estudio "variopinto». Incluso al extenderse a la historia contemporánea de España, permiten matizar la categoría de la presunta «informalidad», al analizar con qué modalidades la historia del género relativiza la diferencia entre las dos formas de sociabilidad; se aboga por lo tanto por un estudio preciso, bistoricizado y crítico. Si en los años setenta y ocbenta del siglo XX los colectivos feministas investigaron su pasado, tienen una posteridad notable: abundan desde hace algunos años los estudios sobre Falange, movimiento obrero y sufragistas, tanto a nivel nacional como, con el desarrollo de la investigación en las Comunidades Autónomas, regional. Y si se puede esbozar una cronología de asociaciones democráticas desde los liberales del siglo XIX basta la bistoria reciente, también podrá la bistoriografía establecer indicios temáticos y proponer estudios de frecuencia.

Palabras Clave: España. Feminismo. Mujeres. Siglos XIX y XX. Sociabilidad.

ABSTRACT: To apply the instruments of the analysis of sociability to Spanish women does not mean merely the application of a comfortable category to a colourful object. Even extending them to the modern history of Spain, these instruments allow nuance in the category of so-called "informality», by analysing the ways in which the bistory of gender blurs the two forms of sociability; a precise, bistoricised and critical study is called for. If in the 1970s and 1980s feminist groups investigated their past, they have bad a notable aftermath: in recent years, studies bave proliferated on the $F a$ lange, on the workers' movement, and on the suffragists, both on the national and (with the development of research in the Autonomous Communities) the regional level. And if one can trace a chronology of democratic associations from the nineteenth-century liberals to recent times, the bistoriography will also be able to establish key themes and statistical studies. 
KEY WORDS: Spain. Feminism. Women. Nineteenth century. Twentieth century. Sociability.

\author{
«¿Qué es feminismo? \\ Redención de la mujer \\ Perfeccionamiento de la sociedad \\ Elevación de la humanidad» \\ (Mundo femenino, $\mathrm{n}^{\mathrm{o}} 1,25-\mathrm{III}-1921$ ) \\ «La subordinación es un placer» \\ (Mujeres españolas, 18-IV-1929)
}

Cuando las sociabilidades en España son, como lo tiende a demostrar este volumen, objeto de producciones científicas importantes y balances repetidos, cabe notar que, hasta una fecha reciente, el instrumento de análisis proporcionado por las obras de Maurice Agulhon no llegó a aplicarse a la «historia de las mujeres». A lo mejor pasa igual con la historia de género en otros países europeos: aparentemente el interés por el asociacionismo femenino es irregular en la historiografía contemporánea.

Basta con mirar el ejemplo francés en el que el tema de las asociaciones se trató en fecha relativamente temprana ${ }^{i}$, reapareció posteriormente alrededor de $1995^{2}$, caso omiso de algunos estudios, y ha sido objeto de coloquios recientes: coloquio Un siècle de vie associative: quelles opportunités pour les femmes? (14-15 de Mayo de 2001, Centro histórico de los Archivos Nacionales de París), Jornada de estudios Des femmes, des associations et des archives (16 de Mayo de 2001, con intervenciones entre otras, de Françoise Blum (Museo social), Annie Metz (Biblioteca feminista Marguerite Durand), Odile Krakovitch (Archivos del feminismo).

El caso de Alemania resulta bastante similar: si la preocupación por la condición femenina dentro del Tercer Reich es precursora ${ }^{3}$, el examen de las asociaciones feministas del siglo XIX y principios del XX tardará algo más en llevarse a cabó .

\footnotetext{
1 FAYET SCRIBE, Sylvie (Ed.): «Les Associations féminines», Pénélope pour lhistoire des femmes, Paris, $n^{\circ}$ 11, 1984; FAYET-SCRIBE, Sylvie: Associations féminines et catholicisme. De la charité à laction sociale, XIX'-XX siècles, Paris, Ed. Ouvrières, 1992.

2 BARD, Christine: Les filles de Marianne. Histoire des féminismes 1914-1940, Paris, Fayard, 1995; para una bibliografía completa, ver este título y THÉBAUD, Françoise: Ecrire l'bistoire des femmes, Fontenay-Saint Cloud, E.N.S. Ed., 1998.

3 Thalmann, Rita: Etre femme sous le Troisième Reich, Paris, Robert Laffont, 1982.

4 Thalmann, Rita (Ed.): Femmes et fascismes, Paris, Tierce, 1986, y La tentation nationaliste, Paris, Tierce, 1990.
}

Hispania, LXIII/2, núm. 214 (2003) 605-620 
A la par, si planteamos el problema en términos ya no de campo de investigación sino de metodología, no se emplean consciente o decididamente la terminología, los conceptos o la categoría de análisis de la «sociabilidad»; así en Francia la propia Christine Bard, cuando habla de las «hijas de Marianne» reivindica sólo una parte de la herencia de Maurice Agulhon, o sea el aporte de éste en materia de estudio de los símbolos de la Repúblicas.. En cuanto a los coloquios de reciente organización, sus preocupaciones metodológicas van por otros derroteros: se trata de poner de realce la peculiar dificultad de acceder a las fuentes y archivos en materia de asociaciones, así como tender a la constitución y la consolidación de centros de archivos.

Reside por lo tanto el problema no tanto en saber si se hacían estudios de sociabilidad sin saberlo, o si muchos estudios recientes aprovechan el término sin hacer funcionar la categoría llegando a aplicarse a «los más variopintos objetos» ${ }^{6}$, como lo analizan ciertos observadores, sino intentar examinar la posible aportación de las tesis de Maurice Agulhon al conocimiento de los colectivos femeninos. Por lo tanto, no tienden esta líneas a la exhaustividad forzadamente impensable en la actualidad.

\section{MOVIMIENTOS FEMINISTAS E INTERÉS POR LA SOCIABILIDAD}

Antes de intentar comprender si la «sociabilidad» funciona como herramienta conceptual renovadora de la historia del género, puede ser útil considerar una posible ecuación entre el apogeo de los movimientos feministas, en un momento dado, y el interés de la investigación por el asociacionismo del pasado. Desde luego, los feminismos europeos - y en larga medida los norteamericanos- de los años 1970 y 1980, entre sus numerosas características (que se pudieran resumir escuetamente como una voluntad asociativa fundada sobre el espontaneismo, la oposición a todas las jerarquías y una reivindicación múltiple y radical) se señalan como el terreno donde germinó la historia de las mujeres.

Ahora bien, la recuperación militante de la historia también tiene tendencias dominantes comunes a los diversos países, a pesar de la diversidad de las corrientes feministas ${ }^{7}$, y de las circunstancias políticas: la atención por las trayectorias individuales, la afirmación de la presencia política de las mujeres en la historia escrita por los historiadores y a fortiori vehiculada por los políticos con visos a menudo uniformadores y nacionalistas. En España, la exigencia de his-

s BARD, Christine: Les filles de Marianne, op. cit., p. 10; AGULHON, Maurice: Marianne au combat, limagerie et la symbolique républicaines, Paris, Flammarion, 3 vols., 1979, 1989 y 2001.

6 CANAL, Jordi: "La sociabilidad en los estudios sobre la España contemporánea: una revisión», en MAZA ZORRILLA, Elena (Ed.): Sociabilidad en la España contemporánea. Historiografía y problemas metodológicos, Valladolid, Universidad de Valladolid, 2002, p. 38.

7. OFFEN, Karen: «Definir el feminismo: un análisis histórico comparativo», Historia Social, Valencia; $n^{\circ}$ 9, Invierno de 1991, pp. 103-135. 
toria de finales de los años 70 se funda en los silencios acumulados de la historiografía reciente: no sólo el silencio de los historiadores acerca del papel de las mujeres («el arquetipo viril de la historia» en términos de la investigadora y militante feminista Amparo Moreno ${ }^{8}$ ), sino también la ausencia de la mujer a su propio ser, dentro del sistema legislativo franquista y, por razones obvias, la reescritura de la historia por la dictadura.

Pero si ciertas características comunes tienden a definir los primeros intentos de historia de las mujeres en Europa a principios de los años ochenta ${ }^{9}$, como la reafirmación de una existencia silenciada, la actuación conjunta de la institución universitaria y de los grupos militantes, el vigor de los enfrentamientos conceptuales, la fragmentación de las primeras aportaciones - «granitos de arena» para Mary Nash, "fase acumulativa» para Françoise Thébaud-, tan sólo una parte de las investigaciones se dedica de hecho al estudio de las asociaciones decimonónicas - caso rarísimo- o dél siglo XX. Se da también el fenómeno de las asociaciones consideradas como referencias obligadas, evidencias sin analizar históricamente hasta una fecha reciente: es así el caso del Lyceum Club ${ }^{10}$.

Tres tipos de asociaciones han sido objeto de los primeros estudios. La voluntad de reafirmar el compromiso social e incluso revolucionario de las españolas es la clave de la interpretación de las conocidas obras, precursoras en todos los aspectos, de Mary Nash; la antología de textos de Mujeres libres (1975) comporta una introducción sobre el funcionamiento y la capacidad afiliadora de la asociación creada en Abril del 36 por médicas anarquistas ${ }^{11}$; y en 1981, la misma preocupación social rige la redacción de la síntesis sobre mujeres y movimiento obrero ${ }^{12}$.

Dentro de la misma corriente de reafirmación de la mujer del pueblo como actora de un proceso de reivindicación y de revolución, se señalan varias ponencias del coloquio celebrado en abril de 1982 por el recién creado Seminario de estudios de la Mujer de la Universidad Autónoma de Madrid [U.A.M.] y gestionado por un colectivo de historiadoras, sociólogas y especialistas de literatura, sin voluntad de protagonismo individual: notemos entre otras aportaciones el trabajo de Marta Bizcarrondo que examina las dificultades de la afiliación de las mujeres al Partido socialista, "partido de hombres», según Michel Ralle, y la contribución de los grupos de más relevante militancia ${ }^{13}$; y en el mismo volumen de actas, un ejemplar estudio de la Unión de Muchachas por

\footnotetext{
8 MORENO SARDÁ, Amparo: Mujeres en lucha. El movimiento feminista en España, Barcelona, Anagrama, 1977.

9 Sobre esos temas, ver Bussy Gentvols, Danièle: «Histoire sociale, histoire des femmes, même débat?», Bulletin d'Histoire contemporaine de lEspagne, Bordeaux, n ${ }^{\circ}$ 17-18, Junio de 1993, pp. 206-217.

10 Si descontamos el primer intento de síntesis de CAMPO AlANGE, María: La mujer en España. Cien años de bistoria (1860-1960), Madrid, Aguilar, 1964, y los recuerdos personales de Caro BAROJA, Julio: Los Baroja (memorias familiares), Madrid, Taurus, 1972.

11 NASH, Mary: Mujeres libres. España 1936-1939, Barcelona, Tusquets, 1975.

12 NASH, Mary: Mujer y movimiento obrero en España (1931-1939), Madrid, Taurus, 1979.

13 BIZCARRONDO, Marta: "Los orígenes del feminismo socialista», en La mujer en la bistoria de España (siglos XVI-XX), Madrid, Seminario de Estudios de la Mujer de la U.A.M., 1984, pp. 137-158.
} 
María Carmen García-Nieto París, trabajo de «sociabilidad formal» antes de la letra: fuentes estadísticas, razones de la constitución del grupo, actividades, planteamientos teóricos, influencia sobre el devenir de las jóvenes madrileñas durante la guerra de España ${ }^{14}$.

O sea que dentro de los colectivos feministas se enraiza el interés por los grupos socialmente progresistas ${ }^{15}$; hasta la forma de la investigación es demostración de esta voluntad de colectivo militante: las relaciones de Mary Nash con Diego Abad de Santillán y los anarquistas del exilio, seminarios o "Colectivo 36» (nombre del equipo dedicado al estudio de la Unión de Muchachas), colectivos que reunían a universitarias y militantes fuera de la institución académica.

En los mismos años, el segundo tipo de asociaciones estudiadas son las organizaciones nacionalistas: en el mismo congreso de la U.A.M., destacan —después de las investigaciones de Antonio Elorza ${ }^{16}$ - los primeros elementos de la tesis doctoral dedicada por Mercedes Ugalde a la asociación vasca Emakume, estudio de las teorías y fuentes útiles así como los modelos (irlandeses en particular) y la variedad de las intervenciones de mujeres afiliadas ${ }^{17}$; pero también se dan, desde el campo del hispanismo francés (Marie-Aline Barrachina en $1979^{18}$ ) y de la militancia española (María Teresa Gallego Méndez en 1985'19), los primeros estudios fundamentales de la Sección femenina de la Falange, o sea la voluntad de comprender las causas de la sumisión femenina en ciertos momentos políticos.

La tercera línea investigadora, fuera de la atracción lógica por el papel revolucionario y de atracción-repulsión por los movimientos de instrumentalización de la población femenina, corresponde a la reactivación de la historia de las sufragistas españolas: Rosa Capel en un estudio precursor reflexiona sobre el voto femenino ${ }^{20}$, Concha Fagoaga anima con un colectivo la conmemoración en 1981 de la obtención del voto el $1^{\circ}$ de Octubre de $1931^{21}$, y a la par, inves-

14 Garcia-Nieto, M. C. y Colectivo 36: «Unión de Muchachas, un modelo metodológico», Ibid., pp. 313-331.

is Ver MOReno SARDÁ, Amparo: Mujeres en lucha, op. cit.; EsCarío Pilar, AlBerdi Inés, LóPEZ-ACCOLTO, Ana Inés: Lo personal es político. El movimiento feminista en la transición, Madrid, Ministerio de Asuntos Sociales/Instituto de la Mujer ( $\left.\mathrm{n}^{\circ} 45\right), 1996$.

16 ELORZA, Antonio: «Emakume: la mujer en el nacionalismo vasco», Tiempo de Historia, Madrid, $\mathrm{n}^{\circ} 38$ Enero de 1978, pp. 4-17.

17 UGalde Solano, Merxe: «Las mujeres en el nacionalismo vasco durante la Segunda República: esquema metodológico», en La mujer en la historia de España, op. cit., pp. 213-223.

18 BARRACHINA, Marie-Aline: La Section féminine de F.E.T. et des J.O.N.S. puis du Mouvement national (origines, genèse, influence), Tesis de doctorado, Universidad de Paris III, 1979.

19 Gallego Méndez, María Teresa: Mujer, Falange y Franquismo, Madrid, Taurus, 1983.

20 CaPel Martínez, Rosa María: El sufragio femenino en la Segunda República Madrid, Comunidad de Madrid, 1992 ( $1^{\text {a }}$ ed., Universidad de Granada, 1979).

21 Ver Bussy Genevors, Danièle: «La mémoire du vote des femmes (1931-1981: une réappropriation», Pandora, Saint Denis, Université Paris VIII, nº 1, 2001, pp. 266-276.

Hispania, LXIII/2, núm. 214 (2003) 605-620 
tiga no sólo el papel inolvidable de Clara Campoamor sino los grupos pacifistas y sufragistas de principios del siglo $\mathrm{XX}^{22}$.

En 1984, Amparo Moreno leía una tesis que obtuvo el premio Clara Campoamor del Instituto de la Mujer: cafirmación de la institucionalización del colectivo a raíz de la instauración de las Comunidades autónomas?, puede ser; pero lo importante es considerar también que parte de la tesis fue publicada en 1986 por la librería-colectivo La Sal de Barcelona y prologada con lirismo y compromiso por María Carmen García-Nieto, en un texto representativo de la relación entre militancia e investigación:

«Quiero y pienso que somos cada vez más las mujeres que hacemos objeto de batalla cultural y política nuestro quehacer académico y profesional [...] sin escisiones ni dicotomías entre [...] lo "personal» y «lo colectivo»; queremos contribuir a la construcción de un discurso histórico [...] que repercuta en la modelación de una vida colectiva en la que "para hacer las cosas» sea preciso ser simplemente humano, mujer y hombre»23.

Tras reconocer, en 1991, la importancia del colectivo interdisciplinario de la investigación - Centre d'Investigació Histórica de la Dona 1982, y seminarios de la U.A.M. o de otras ciudades ${ }^{24}$ - Mary Nash expresó algún tiempo más tarde cierta inquietud respecto a la trasposición del militantismo feminista de un período a otro:

«Desde la superación de posturas doctrinarias queda claro que las propuestas del feminismo de finales del siglo XX no pueden condicionar la formulación de un programa feminista de principios de siglo»25.

Pero sin embargo, pocos ejemplos de la confusión han podido darse en lo que toca a la historia contemporánea; ya Marie-Aline Barrachina en 1982 subrayaba el «riesgo [...] de hacer de la historia de las mujeres una historia del feminismo, o una historia feminista militante y por tanto parcial, en el doble sentido de la palabra» ${ }^{26}$. Las convicciones sociales no han quitado el rigor del estudio de los primeros grupos que dentro del contexto feminista radical, han sido objeto de in-

22 FAGOAGA, Concha: La voz y el voto de las mujeres, Barcelona, Icaria, 1985; FAGOAGA, Concha y SAAVEDRA, Paloma: Clara Campoamor. La sufragista española, Madrid, Instituto de la Mujer, 1986.

23 García-Nieto París, María Carmen: «Prólogo» (Febrero de 1986) a MORENo, Amparo: El arquetipo viril protagonista de la bistoria. Ejercicios de lectura no androcéntrica, Barcelona, La SalEdiciones de Les Dones (Col. Cuadernos inacabados, 6), 1986.

${ }^{24}$ NASH, Mary: «Dos décadas de historia de las mujeres en España: una reconsideración», Historia Social, Valencia, $\mathrm{n}^{\circ}$ 9, Invierno de 1991, p. 141.

${ }_{25} \mathrm{NASH}$, Mary: «Experiencia y aprendizaje: la formación histórica de los feminismos en España», Historia Social, Valencia, no 20, Otoño de 1994, p. 158.

26 BARRACHINA, Marie-Aline: «Ventajas y problemas que ofrece la entrevista para el estudio del período de la Segunda República», en La mujer en la bistoria de España, op. cit., p. 225. 
vestigación. Las tres tendencias del estudio de la afirmación obrera, feminista y, de modo complementario y perfectamente lógico, la reflexión sobre el período franquista que acaba de terminar, en aquel entonces, confirman el arranque social del redescubrimiento del papel de los colectivos femeninos.

Queda, por lo tanto, el ejemplo feminista de la transición democrática una confirmación de la capacidad del movimiento social, en momentos claves, para fomentar la creación de asociaciones concretas y la investigación relacionada con el tema: Marie-Claude Lécuyer indica en una síntesis reciente la situación de los estudios sobre la sociabilidad formal y constata, a partir de observaciones de investigadores franceses, la conjunción entre el momento histórico (Mayo de 1968, llegada de los socialistas al poder en 1981), la multiplicación de asociaciones (40.000 asociaciones creadas en 1982) y la creación en 1981, de una «Société française des chercheurs sur les associations» ${ }^{27}$.

\section{ASPECTOS DE LA SOCIABILIDAD FORMAL}

La fermentación del asociacionismo por coincidencia con un ideal social y político merecería analizarse a lo largo de la España contemporánea. Lo que se acaba de decir de modo rápido acerca de la transición democrática, aparentemente creadora de asociaciones femeninas pero poco duraderas (hasta 1979 para Marie-Aline Barrachina ${ }^{28}$, y 1983 para las investigadoras del Ministerio de Asuntos Sociales que examinan la situación hasta la creación oficial del Instituto de la Mujer ${ }^{29}$ ), se verifica en diferentes momentos, cuya cronología queda todavía por establecer de modo fino.

Estos momentos coinciden con la afirmación política del liberalismo y, en el siglo XX, de la democracia: así lo demuestra la época de fundación de liceos (el primero en Madrid en 1837) que hasta 1850 van a atraer a hijas, hermanas y esposas de socios, sin lograr borrar una desigualdad numérica importante entre los dos sexos ${ }^{30}$.

Ya en aquella primera época de sociabilidad liberal se privilegiaba el papel de la mujer (siempre en singular en aquel entonces) como apoyo a la nación mediante la maternidad y la familia:

\footnotetext{
27 LÉCUYER, Marie-Claude: «Las aportaciones de los historiadores e hispanistas franceses: balance de una década», en MAZA ZORRILlA, Elena (Ed.): Sociabilidad en la España contemporánea, op. cit., p. 11.

28 BARRACHINA, Marie-Aline: «Vindicación feminista: aboutissement d'un processus, constitution d'un réseau", en BuSSY GENEvOIS, Danièle (Ed.): Lès Espagnoles dans Ihistoire. Une sociabilité démocratique (XIX'-XX' siècles), Saint Denis, P.U.V., 2002, pp. 187-204.

29 ESCARío, Pilar, AlBERDI, Inés, LóPEZ-ACCOLTO, Ana Inés: Lo personal es político, op. cit., p. 333 y sig.

30 LÉCUYER, Marie-Claude: «Femmes et sociabilité au XIX ${ }^{\mathrm{e}}$ siècle: le cas des Liceos», en BUSSY Genevois, Danièle (Ed.): Les Espagnoles dans l'bistoire, op. cit., pp. 31-49.
} 
«i[...] Y cómo si fuese posible que llenara sin mengua los deberes de hija, esposa y madre la que no ha podido cultivar su entendimiento!»31.

Otro ejemplo liberal, durante el Sexenio, pudiera ser la voluntad catalizadora de la revista La Mujer, alrededor de Faustina Sáez de Melgar, en 1871 - cuyo primer intento de prensa, La Violeta en 1863, en tiempos de Isabel II, había correspondido con el sueño de crear un grupo de lectoras asociadas y no sólo suscriptoras-, a favor de «los imprescindibles deberes sociales encomendados a la mujer ${ }^{32}$. Pero en la voluntad de conquistar un público, distinguiéndose a la vez de «la masa» inquietante y de los carlistas que hacen desempeñar a la mujer tareas («políticas»), que la redacción juzga incompatibles con la dignidad del sexo, sólo hay los esbozos de un asociacionismo: un discurso y un órgano de prensa alentadores.

Paradójicamente, combates que hubieran podido unir una franja liberal incluso durante la primera Restauración, no consiguieron, a pesar de los esfuerzos de Concepción Arenal —única mujer española- y de compañeros liberales, atraer a las mujeres ${ }^{33}$.

Sin embargo, las teorías de Maurice Agulhon van a ser sumamente convincentes para el estudio de asociaciones formales, cuyo conocimiento va madurando en los años recientes. Algunos ejemplos, de fecha e ideología muy diferentes, pueden traerse a colación; una clasificación rápida llevaría a distinguir las asociaciones decimonónicas liberales de las asociaciones «feministas» a principios del siglo XX, durante la Segunda República o a finales del franquismo y de las asociaciones de masa antifascistas de los años treinta - entre las más estudiadas, aunque las primicias del movimiento supondrían una síntesis de los conocimientos actuales y la aportación de testimonios complementarios.

Tomemos tres clases de colectivos: uno de apoyo a la asociación masculina preexistente, otros exclusivamente femeninos y por fin, un ejemplo de asociación de extrema derecha - menos estudiada por supuesto que la Sección femenina - que se inició como feminista, terminó sojuzgada por una presidencia masculina y la doble autoridad eclesiástica y política.

El primer caso es relevante, pues se trata de la masonería; la influencia del protestantismo en España como motor de las agrupaciones femeninas se queda de momento a nivel de hipótesis — propuesta por Jean-Louis Guereña ${ }^{34}$-; en

31 Discurso de LAmARCA, Luis, en el Liceo de Valencia 1841 (Ibid., p. 37).

32 F. F., «Nuestra misión», La Mujer, nº 3, 24-VI-1871, p. 1.

33 Sobre este punto, ver GUERENA, Jean-Louis: «La cause abolitionniste sous la Restauration, facteur associatif (1877-1892)?», en BUSSY GENEvoIs, Danièle (Ed.): Les Espagnoles dans lhistoire, op. cit., pp. 51-74.

34 GUEREN̄A, Jean-Louis: «La masonería española frente a la prostitución durante la Restauración», en FERRER BENIMELI, J. A. (Ed.): La masoneria española en el 2000. Una revisión bistórica. IX Symposium Internacional de Historia de la Masonería Española. Segovia, del 18 al 22 de octubre de 2000, Zaragoza, Gobierno de Aragón (Colección «Actas», 55), 2001, t. II, pp. 641-662.

Hispania, LXIII/2, núm. 214 (2003) 605-620 
Francia, ha provocado el interés de algunos investigadores, como lo pone de manifiesto la bibliografía y la existencia de un reciente libro que abarca casi dos siglos. Geneviève Poujol trata de desarrollar lo individual y lo colectivo en el relativo protagonismo femenino dentro del protestantismo francés, a priori defensor de posturas igualitarias ${ }^{35}$.

Pero la masonería, objeto de admirables investigaciones, también permite hacer funcionar las categorías de Maurice Agulhon, y de modo más novedoso, al aplicarse a las logias femeninas, que se fueron creando a finales del XIX, después de admitir mujeres en ciertas logias masculinas; reglamentos, sociología de las masonas, valor simbólico de los nombres - llegando a esbozar un ideal ético - son datos ahora reunidos que ponen en perspectiva elementos conocidos acerca de personalidades tan interesantes como Rosario de Acuña, Amalia y Ana Carbia o Angeles López de Ayala ${ }^{36}$.

Tal aproximación a asociaciones formales permite completar la importancia de la masonería en los grupos laicistas y sufragistas de principios de siglo en España y ayuda a establecer enlaces entre personalidades o grupos que aparecen en lugares tan diferentes como Madrid, Málaga o Valencia, y forman el fondo del movimiento laicista español, uno de los núcleos del republicanismo incipiente ${ }^{37}$.

Diferente es el caso de las agrupaciones feministas, que rara vez se autoproclaman como tal a pesar de su compromiso, hasta después de la transición post-franquista: Asociación Nacional de Mujeres Españolas [A.N.M.E.] (1918), Cruzada de Mujeres (1921), Unión de Mujeres (1918), Unión Republicana Femenina (1932), Asociación Femenina de Educación Cívica [A.F.E.C.] (1932), entre las más sobresalientes, llegando el Lyceum Club (1926) a la postura más exagerada, hasta la indefinición en el título público (en el Reglamento, aparece como Lyceum Club Femenino Español).

Con los archivos personales, los testimonios y la posibilidad de cruzar la documentación y las miradas, la investigación permite un estudio de sociabilidad satisfactorio del Lyceum Club y cada vez más preciso de las demás asociaciones. La formalidad de estas asociaciones se nota en la programática, los reglamentos, las declaraciones colectivas, los debates internos, los cursillos y las conferencias, y, en muchos casos, en la existencia de un boletín o de una revista (Redención -1917- Valencia, de la Liga del Progreso de la Mujer, de las hermanas Carbia; Mundo Femenino -1921- para la A.N.M.E.; Cultura integral y femenina

35 Poujol, Geneviève: Un féminisme sous tutelle. Les protestantes françaises 1810-1960, Paris, Les Editions de Paris Max Chaleil (Coll. Bibliothèque protestante), 2003.

36 RANDOUYER, Françoise: «Les franc-maçonnes (1868-1898)», en BUSSY GENEVOIS, Danièle (Ed.): Les Espagnoles dans l'bistoire, op. cit., pp. 127-144.

37 RAMOS, María Dolores: «La cultura societaria del feminismo libre-pensador (1895-1918)», en Bussy GENEVOIS, Danièle (Ed.): Les Espagnoles dans l'histoire, op. cit., pp. 103-124; FAGOAGA, Concha: «De la libertad a la igualdad, laicistas y sufragistas», en SEGURA, Cristina y NIELFA, Gloria (Eds.), Entre la marginación y el desarrollo: bombres y mujeres en la bistoria. Homenaje a María Carmen García-Nieto, Madrid, Instituto de Investigaciones feministas-Ediciones del Orto, 1996, pp. 171-198. 
-1933- para la A.F.E.C. y otras organizaciones profesionales médicas, entre otros ejemplos).

Es modélica - pero no única - la organización del Lyceum Club por su referencia a la sociabilidad anglosajona: lugar cultural con conferencias y biblioteca, comité social, espacio de solidaridad, llega a reunir una élite cultural, política sin proclamarlo y a ser capaz de promover otras asociaciones -en particular el Lyceum Club de Barcelona (1931) y de San Sebastián (1932) y los lazos con la A.F.E.C. ${ }^{38}$ - O sea, que todas estas asociaciones se conciben aquí una voluntad de progreso nacional -y político en el caso de algunas de ellas decididamente republicanas 39 -, lo que se verifica en particular con la obtención del sufragio en 1931:

«[...] Un ambiente social adecuado — producto de enormes esfuerzos realizados por los núcleos femeninos más audaces de nuestro país- ha transformado el sentir de los españoles con respecto a su propio valer intelectual, moral, social» ${ }^{40}$.

Esta perspectiva - testimonio de la segunda presidenta de la A.N.M.E. y directora de su boletín Mundo femenino, desde 1921 - permite también matizar una aprensión de la sociabilidad formal que tendería a hacer de las asociaciones un ghetto femenino. Buen ejemplo de ello son los contactos bastante bien conocidos ahora entre la Juventud Universitaria Feminista [J.U.F.] —en este caso «feminista» - fundada por la Doctora Elisa Soriano, por otra parte miembro fundador de la A.N.M.E., y la Unión Nacional de Estudiantes, partícipe de la creación de la Confederación internacional de estudiantes (Estrasburgo, 1919) y actor fundamental del Congreso internacional de Praga en 1921. En este contexto de la post-guerra, será Victoria Kent - futura diputada de la Segunda República - la representante no sólo de dos organizaciones españolas, femeninas no mixtas, sino también del gobierno español, que la designó para ir a Praga. A ella le tocó subrayar la labor de la J.U.F. «por el mejoramiento y engrandecimiento de la mujer española, que es lo único que se propone esta Asociación» y la misión internacional:

«Personal y colectivamente tenemos el alma llena de optimismo [...]. Reunidos en ese Congreso estudiantes de todas las partes del mundo [...] en una fraternal comunión de los espíritus [...], hemos robustecido en nuestro cerebro la idea

38 FAGOAGA, Concha: «El Lyceum Club de Madrid, élite latente», en BuSSY-GenEvoIs, Danièle (Ed.): Les Espagnoles dans l'bistoire, op. cit., pp. 145-167. Incluye el cuadro de las socias y el Reglamento de la asociación.

39 Sobre la evolución conservadora de la A.N.M.E., ver Bussy Genevors, Danièle: «Les Espagnoles ou le pacifisme de l'entre-trois-guerres", en THALMANN, Rita: La tentation nationaliste, op. cit., pp. 115-135.

40 ASAS MAnterola, Benita: La Libertad, Diciembre de 1926, cit. por FAGOAGA, Concha: «El Lyceum Club de Madrid», op. cit., p. 39.

Hispania, LXIII/2, núm. 214 (2003) 605-620 
de una civilización mejor que la pasada; hemos visto que el secreto de la paz no está en las oficinas del Estado, ni en las embajadas, ni en los ejércitos; el secreto de la paz lo tienen los estudiantes de todos los países; la culpa de la guerra la tienen todos los estudiantes del mundo [...]»41.

Pero el asociacionismo no es sólo idealista y democrático; lo particularmente sugestivo de las categorías de Maurice Agulhon es que se aplican al asociacionismo tanto liberal y republicano (el historiador francés ha manejado el concepto como clave de la comprensión de los republicanos del Sur de Francia) como conservador; por eso, puede ser de cierta utilidad examinar aquí el ejemplo de asociaciones ultraderechistas, en un momento político reformador como la Segunda República. A priori, si divergen los objetivos, no difieren fundamentalmente los motivos para explicar la fundación de colectivos. Así, la asociación Aspiraciones - cuyas primeras manifestaciones coinciden con la publicación de la revista homónima en enero de 1932 - tiene por objetivo proclamado una aspiración feminista, o sea la educación cívica de las españolas tras «otorgarles» el voto en Octubre de 1931; de la asociación femenina formal, tiene todos los elementos: lugar de encuentro, reglamento, biblioteca, cursillos, prensa.

Ahora bien, las directoras -madre e hija de una familia de ex-colonos cubanos, militantes de la Unión patriótica de Primo de Rivera - tienen por objeto nacional formar a las mujeres en el antirrepublicanismo, el antisemitismo y el anticomunismo; su capacidad afiliadora, respecto a las asociaciones contemporáneas - sólo las asociaciones antifascistas y anarquistas alcanzarán cifras muy importantes de afiliadas - es rapidísima (5.000 mujeres en Madrid hasta Julio de 1932). Saben desviar el sufragio hacia otras modalidades (clasificar el cuerpo electoral en "adictos» a su causa) y actuar con una brutalidad destructora de los estereotipos de la feminidad vigentes: boicotear, redactando listas negras de denuncia, a los comerciantes «judíos» o supuestamente tales; organizar exposiciones falsificadas y sangrientas de «Rusia»; convocar mítines en zonas marcadamente de izquierdas (como Villa de Don Fadrique, en 1933) y organizar misas de exaltación nacionalista en la Basílica del Cerro de los Angeles, sin olvidarse de destruir la «basura» de los kioscos de prensa $\longrightarrow$ sea la prensa de izquierdas-. Consecuencia lógica de la creación de Aspiraciones será su participación en el golpe de Estado del 10 de Agosto de 1932 — de donde la suspensión de la revista y el arresto de la directora, que logrará publicar ulteriormente Realidades-: ino había consistido su primera actuación, en proponer «linchar» a los responsables de los acontecimientos de Castilblanco el 31 de Diciembre de $1931^{42}$ ?

41 Discurso de Kent, Victoria, en RAmos, María Dolores: «El informe del Congreso Internacional de Estudiantes de Praga o la huella de la Institución Libre de Enseñanza en Victoria Kent (1921)», Arenal, Granada, vol. 5, n² 2, Julio-Diciembre de 1998, pp. 413-431.

42 BuSSY Genevols, Danièle: «Expresión y represión: el caso de Aspiraciones (1932-1935), en TUNÓN DE LARA, Manuel (Ed.), Comunicación, cultura y política durante la República y la guerra civil, 
La comodidad de una categoría analítica lo suficientemente flexible como para adaptarse a asociaciones de tipo político diferente es evidente y el examen de los reglamentos - caso de preservarse-, de la lista de los cursilloś (dactilografía, idiomas, conferencias políticas) y de las fotografías de banquetes ayudan a la comprensión de la construcción de los colectivos femeninos.

\section{¿FORMAL O INFORMAL?}

Por cierto, las asociaciones formales españolas, a pesar de los progresos recientes de la historia, supondrían investigaciones complementarias, y más aún, las asociaciones religiosas (en particular Acción Católica) ${ }^{43}$; pero otra preocupación esencial, que toca la sociabilidad femenina, consiste en saber cómo aprovechar la categoría de sociabilidad informal. Si Maurice Agulhon propuso distinguir el campo del asociacionismo de formas de sociabilidad más espontáneas hubo dos tendencias entre sus seguidores: muchos intentaron - y son numerosos entre los investigadores españoles e hispanistas - precisar la frontera y matizar lo que pudiera aparecer como una oposición somera entre las dos categorías (véanse los estudios de Michel Ralle sobre la calle, Jorge Uría, Gérard Brey o Aron Cohen sobre la taberna, para evocar algunos ejemplos reconocidos); pero también hubo estudios menos sutiles tendiendo a suponer la existencia de una frontera impermeable entre formalidad y espontaneidad, y transformar una notable reflexión de Agulhon en mera comodidad metodológica.

En estas materias, un estudio modélico, como el de Jean François Botrel aplicado a los casinos leoneses ${ }^{44}$, merecería encontrar un equivalente para la sociabilidad femenina: un rastreo por la prensa de provincias, como la de Aragón, por ejemplo, a finales del siglo XIX, abre alguna pista para la investigación; en El Pirineo Aragonés (sección "revista de la semana») de la década de los ochenta del siglo XIX o El Heraldo de Aragón (década de los noventa), reseñas de fiestas, ecos de casinos, actos "por la cultura», crónicas de «noticias» o de «La región», sin olvidar la sección teatral o parroquial, indican a veces una participación colectiva femenina de interés; si un rastreo de esta clase requiere cierta terquedad investigadora y capacidad para aceptar frustraciones, irá construyendo una imagen sugestiva de la visibilidad/invisibilidad de la mujer en la vida social urbana, que pudiera aplicarse a otras regiones.

Bilbao, Servicio Editorial Universidad del País Vasco, 1990, t. II, pp. 234-245; Álvarez ChillidA, Gonzalo: El antisemitismo en España. La imagen del judío (1812-2002), Madrid, Marcial Pons Ediciones de Historia, 2002.

43 Ver, no obstante, el estudio reciente de BLASCO, Inmaculada: Paradojas de la ortodoxia. Politica de masas y militancia católica femenina en España (1919-1939), Zaragoza, Prensas Universitarias de Zaragoza, 2003.

44 Botrel, Jean-François: «La sociabilidad provinciana a mediados del siglo XIX: el casino leonés», en FUENTES, Juan Francisco y ROURA AULINAS, Lluís (Eds.): Sociabilidad y liberalismo en la España del siglo XIX. Homenaje al profesor Alberto Gil Novales, Lleida, Ed. Milenio, 2001, pp. 277-290.

Hispania, LXIII/2, núm. 214 (2003) 605-620 
La primera dificultad, desde luego, para aprehender la sociabilidad femenina informal, es su débil eco informativo. Por lo tanto, el estudio se ha de desplazar hacia otros campos y aprovechar los intersticios de la investigación, por ejemplo en el campo del movimiento obrero; acerca de la situación políticosocial, la importancia de las reflexiones de María Dolores Ramos, ya aludidas, acerca del feminismo libre-pensador, merece destacarse:

«Esas prácticas [una experiencia colectiva de la sororidad] implican la ayuda mutua, el reconocimiento de voces de autoridad entre las mujeres [...], la creación de redes familiares y vecinales $[\ldots ..]{ }^{45}$.

En otro ámbito, Michel Ralle, al examinar el «meeting de mujeres» en el Circo Ecuestre de Barcelona en 1891, como señal de reconocimiento de la importancia creciente de las mujeres en la industria textil catalana, intenta comprender la interpenetración de las redes de sociabilidad; pone de realce los ecos de una sociabilidad informal y las aspiraciones simultáneas a la organización, subrayando la permeabilidad - o la necesaria relación - entre informalidad y asociacionismo. Si Michel Ralle subraya también la insuficiencia informativa de la prensa general, tendiendo a privilegiar bailes de cigarreras o motines, indica la actitud de la prensa anarquista; así ve El Productor «la hermosa matrona y [...] la honesta doncella catalanas resueltas a luchar por la felicidad de los seres queridos de su corazón» (1891) y, en 1901, a las mujeres tratando de abrirse paso fuera de la sociabilidad familiar y aspirando a una sociabilidad formal, femenina (anarquista en este caso):

\begin{abstract}
«Unámonos todas dentro de una organización puramente nuestra, mantenida y dirigida por nosotras mismas»46.
\end{abstract}

También hay que indagar en los conocimientos que proporcionan los testimonios, correspondencias o autobiografías para apreciar la dosis de espontaneidad que puede, a la larga, desembocar en una asociación formal: el papel de la manifestación o de la fiesta, su grado de relación con un partido o una asociación — $\longrightarrow$ su espontaneidad aparente - han sido objeto de estudio en un número del Bulletin d'Histoire Contemporaine de l'Espagne a cargo del Equipe de Recherches sur les Sociétés et Cultures de l'Espagne Contemporaine [E.R.E.S.C.E.C.]; en este número de la revista, se examinan las fiestas de la Dictadura y la Segunda República desde la perspectiva de la implicación, el compromiso y la independencia posible de las mujeres ${ }^{47}$. Y el tema resurge en

45 RAMOS, María Dolores: «La cultura societaria del feminismo libre-pensador», op. cit., p. 113.

46 El Productor, Barcelona, 7-XII-1901, cit. por RALLE, Michel: «La féminisation industrielle en Catalogne (1870-1910): un enjeu pour l'anarchisme», en Bussy GeNEvoIs, Danièle (Ed.): Les Espagnoles dans lbistoire, op. cit., p. 96.

47 BusSY GenevoIs, Danièle: «Dictature, Seconde République: la fête est-elle du féminin?», en Bussy Genevois, Danièle, Guereña, Jean-Louis, RALle, Michel (Eds.): Fêtes, sociabilités, politique 
investigaciones recientes sobre la capacidad catalizadora de la fiesta militante del 8 de Marzo, en una ciudad como Zaragoza ${ }^{48}$.

¿Cómo determinar en una combinación de causalidades el peso de la amistad y la sororidad? Clara Campoamor funda, en Diciembre de 1931 o en Enero de 1932, la Unión Republicana femenina, con el propósito de crear «una escuela de ciudadanía»; pero la idea se le ocurrió en una fiesta-homenaje de amigas republicanas (por eso las dos fechas indicadas). María Lejárraga conoció la sociabilidad femenina a través del marco institucional de la Escuela Normal de Maestras y la mixta mediante las charlas amistosas de las Casas del Pueblo belgas; desempeñó un papel clave de enlace con las asociaciones femeninas españolas e internacionales después de la Primera Guerra Mundial ${ }^{49}$. ¿Por qué entonces esperar la República para crear la A.F.E.C., y definirla en términos más afectivos que políticos? ¿Qué afirmación personal buscar en ella después de redactar libros de su marido Gregorio Martínez Sierra, ya antes de ser elegida diputada del P.S.O.E. por Granada?:

«Un grupo de amigas, apenas pasarían de veinte, decidió crear un hogar espiritual [...] un rincón en el cual las mujeres asociadas pudieran en igualdad perfecta, en solidaridad absoluta, en comprensión total-y apasionada, sentir, y discutir sus problemas $[\ldots]$... 50 .

La palabra «hogar» empleada por María Lejárraga suscita una serie de interrogantes, acerca de la relación con la privacía de la sociabilidad femenina, que pudiera reducir el campo de la formalidad asociativa a pura extensión de las labores propias de su sexo, según rezaban los conservadores de uno y otro siglo. Merecen por lo tanto examinarse más de cerca el ejemplo de asociaciones formales con visos a instrumentalizar a las mujeres, que van a jugar conscientemente con la ambigüedad, como lo hizo constantemente José María Pemán; así, durante la Segunda República:

«En toda España las mujeres se preparan alegres para sus bodas con el voto. Con el mimo con que doblarían la ropa de un trousseau de novias, organizan sus ficheros, sus listas, sus intervenciones» 51 .

dans lEspagne contemporaine, Número monográfico del Bulletin d'Histoire Contemporaine de lEspagne, $\mathrm{n}^{\circ}$ 30-31, Diciembre de 1999-Junio de 2000 [2002], pp. 103-118.

48 ILLION, Régine: «L'Internationale de la fête: le 8 mars 1936», en BuSsy GENEVOIs, Danièle (Ed.): Les Espagnoles dans l'bistoire, op. cit., pp. 208-221.

49 ManTilla Quiza, María Jesús: «María Lejárraga y el asociacionismo femenino 1900 1936», en AGULERA SASTRE, Juan (Ed.), María Martínez Sierra y la República: ilusión y compromiso, Logroño, Instituto de Estudios Riojanos, 2002, pp. 83-101.

so "Asociación femenina de Educación Cívica», Cultura integral y femenina, nº 1, 15-I-1933, p. 15; sobre la biografía de María Lejárraga, ver RODRIGO, Antonina: María Lejárraga, una mujer en la sombra, Madrid, Edic. Vosa, 1994.

s1 «Votos e ideas», Ellas, n $1,25-\mathrm{V}-1932$, p. 6.

Hispania, LXIII/2, núm. 214 (2003) 605-620 
Igual - pero con una clara voluntad de protagonismo femenino- las presidentas de Aspiraciones, si preconizan que las lectoras se olvidan de hacer punto para hacer «Religión, Patria, política, política y política» ${ }^{52}$, juegan con el vocabulario del hogar para expulsar a judíos y masones, como Isabel la Católica:
«Barramos las mujeres
Barramos con furor,
A todos los canallas
Que arruinan la Nación»53.

Pero las propagandistas y diputadas parecían alejarse del hogar y experimentaban la fruición de contactar con colectivos convertidos en masas, como lo subrayó por ejemplo Pilar Careaga, la primera ingeniera, propagandista del «ideal socio-católico»:

«El sentir la vibración de miles de personas [...] me ha producido un placer inmenso» ${ }^{54}$.

$\mathrm{Al}$ tener que renegar de su capacidad interventora al final de la guerra civil, aceptaron el que el asociacionismo de derechas se fundara en la subordinación a la jerarquía masculina - lo que experimentaron con creces las presidentas de Aspiraciones.

Considerar que este roce entre sociabilidad femenina y espacio privado aleja a las mujeres de un compromiso democrático no se ha confirmado por la investigación; por eso son de sumo interés estudios recientes dedicados a formas particulares de resistencia en tiempo de la dictadura franquista. Así se puede observar cómo, con el relevo generacional, se afirman formas de paso del ámbito familiar al espacio político en los años sesenta del siglo $\mathrm{XX}^{55}$, lo que ha de fomentar, por cierto, las asociaciones de finales del franquismo, pero también permitir crear asociaciones formales enlazando con grupos feministas de antes de la guerra civil: particularmente sugestiva en este aspecto es la relación establecida por las juristas en 1971 con sus antecesoras, estudiantes en los años treinta ${ }^{56}$.

De hecho, desde el principio de la dictadura, las mujeres habían sabido aprovechar las formas de la cotidianidad para oponerse al régimen. A veces la resistencia puede pasar por las relaciones de familia - así, la proximidad sentimental o ideológica con los «vencidos»; pero también por actitudes de rebel-

\footnotetext{
52 Aspiraciones, n 30, 29-VI-1934, p. 30.

53 «Con la escoba en la mano», Aspiraciones, no 3, 30-XI-1933, p. 7.

54 «Una conversación con Pilar Careaga», Ellas, n 1, 29-V-1932, p. 2.

ss Moreno SARDÁ, Amparo: «Sociabilidad femenina y feminista en la implantación de la sociedad de consumo (los años sesenta y setenta)», en BuSSY GENEvoIs, Danièle (Ed.): Les Espagnoles dans l'bistoire, op. cit., pp. 237-255.

56 Ruiz Franco, María del Rosario: «La Asociación Española de Mujeres Juristas durante el Franquismo», en Bussy GenevoIs, Danièle (Ed.): Ibid., pp. 169-185.
} 
día aparentemente más «banales»; como se ha estudiado para el caso aragonés, en el medio rural, y que ha de llevarlas a las mujeres después a ayudar a reconstruir partidos clandestinos:

«[...] Muchas mujeres asumieron la función de denunciar las injusticias y defender la dignidad y el derecho a vivir conforme a las normas internas de la comunidad (unas normas que suponían solidaridad con quien iba a pedir asilo, como eran los guerrilleros, derecho a la seguridad [...] y derecho a realizar las labores impuestas por un régimen represivo)»57.

Sociabilidad informal, todavía, es la misma que llevará a las españolas a establecer redes de solidaridad a la puerta de las cárceles o penales, a unirse por el gesto, el canto o el silencio, como las alemanas del Tercer Reich: se trata de oponerse, a pesar de todo, al régimen instrumentalizador.

Aplicar los instrumentos de análisis de la sociabilidad a las mujeres españolas no significa, por lo tanto, contentarse con la aplicación de una categoría cómoda a un objeto de estudio «variopinto». Incluso al extenderse a la historia contemporánea de España, permiten matizar la categoría de la presunta «informalidad", al analizar con qué modalidades la historia del género relativiza la diferencia entre las dos formas de sociabilidad; se aboga por un estudio preciso, historicizado y crítico.

Si en los años setenta y ochenta del siglo XX los colectivos feministas investigaron su pasado, tienen una posteridad notable: abundan desde hace algunos años los estudios sobre Falange, movimiento obrero y sufragistas, tanto a nivel nacional como regional, con el desarrollo de la investigación en las distintas Comunidades Autónomas ${ }^{58}$. Y si se puede esbozar una cronología de asociaciones democráticas desde los liberales del siglo XIX hasta la historia reciente, también podrá la historiografía establecer indicios temáticos y proponer estudios de frecuencia.

Y al echar abajo los estereotipos más reiterativos y conservadores (ino decía un diputado radical de la Segunda República que las mujeres se asociaban sólo «para beber chocolate»?), contribuirá también el estudio de la sociabilidad femenina demostrar las posturas mayoritariamente democráticas de los colectivos de las mujeres españolas y a acentuar el compromiso de la historia.

57 YUSTA RODRIGO, Mercedes: Guerrilla y resistencia campesina. La resistencia armada contra el franquismo en Aragón (1939-1952), Zaragoza, Prensas Universitarias de Zaragoza, 2003, p. 243. Ver también de la misma autora, "La resistencia al franquismo de las mujeres aragonesas (1939-1950)», en Bussy GenEvoIs, Danièle (Ed.): Les Espagnoles dans lhistoire, op. cit., pp. 223-235.

58 Algunos ejemplos: BLASCO HERRARU, Inmaculada: Armas femeninas para la contrarrevolución: la Sección femenina de Aragón (1936-1950), Málaga, Universidad de Málaga-Atenea, 1998; ILLION, Régine: Mujer, política y sindicalismo Zaragoza, 1931-1936, Zaragoza, Institución Fernando el CatóliCo, 2003; FAGOAGA, Concha (Ed.): 1898-1998. Un siglo avanzando hacia la igualdad de las mujeres, Madrid, Comunidad de Madrid. Dirección General de la Mujer, 1998.

Hispania, LXIII/2, núm. 214 (2003) 605-620 